\title{
Assessment of Child Physical Abuse among Mothers in Mala A Fandi Health Care Centre/Erbil City
}

\author{
Hanaa O. Saadi ${ }^{1 *}$, Yasin K. Amin², Abass A. Ahmed ${ }^{3}$ \\ ${ }^{1}$ Department of Midwifery, Erbil Medical Technical Institute, Erbil Polytechnic University, Erbil, Kurdistan region, Iraq, ${ }^{2}$ Medical Research \\ Center, Hawler Medical University, Erbil, Kurdistan Region, Iraq, ${ }^{3}$ Department of Pediatric, College of Medicine, Hawler Medical University, \\ Erbil, Kurdistan Region, Iraq
}

\author{
${ }^{*}$ Corresponding author: \\ Hanaa O. Saadi, \\ Department of Midwifery, \\ Erbil Medical Technical \\ Institute, Erbil Polytechnic \\ University, Erbil, \\ Kurdistan region, Iraq. \\ E-mail: hospital73@yahoo. \\ co.uk
}

Received: 03 March 2021

Accepted: 24 June 2021

Published: 30 December 2021

DOI

10.25156/ptj.v11n1y2021.pp12-16

\section{A B S T R A C T}

Child physical abuse is an important cause of pediatric morbidity and mortality and is associated with major physical and mental health problems that can extend into adulthood. The main research purpose was to assess sociodemographic characteristics of mothers and find out the most common types and physical abuse among children. This descriptive study is conducted on Mothers of Abused Child at Mala A fandi Health Care Centre in Erbil city of Kurdistan region of Iraq. A convenient sampling was used to choose 100 Mothers who visited particular health center. Questionnaire was used as a tool for collecting data from Mothers who have children $<15$ years old visited the Health center and who did consent informed. Findings showed that $(40 \%)$ of the mothers' ages were between 30 and 39 years and had a primary certificate, $(77 \%)$ of mothers that were in nuclear family types, a majority of them were unemployed. In addition to that, more than $40 \%$ of mothers used twisted the child's ear, pinched the child, and slapped the child's faces or head. This study concluded that the level of education of mothers, as well as number of child in family, have a pivotal role in using physical abuse. Therefore, family planning and educating mothers may decrease the degree of incidence of child abuse Kurdistan region of Iraq

Keywords: Child; Mothers; Physical abuse types; Socio-economic

\section{INTRODUCTION}

Children are defined as a group of people that their ages are not more than 18 years old (UNICEF 2019). Children need clear boundaries and clear idea that their parents are looking after them to remain safe. Nevertheless, abused child are not expected how their parents will act (Devi and Yadav, 2016). However, children are group that needs more protection than other groups of people because of their characteristics (Centers of Disease Control and Prevention, 2010). For this reason, many national and international regulations have been made in order to ensure that children are protected at a high level (Devi and Yadav, 2016). However, in spite of numerous arrangements, abuse and neglect cases are progressively becoming a chief health problem in the world and in the Kurdistan region of Iraq.

According to (Mulita, 2014), it is government's responsibility to protect the child from maltreatment by parents or others responsible for the care of the child. Abuse child reflects the moral sensibilities of society. Based on (World Health Organization, 2014) statement that maltreatment in another word abusing towards a child can be defined as any physical and/or emotional maltreatment that may really or potentially lead to a negative impact on the child's life, growth and development; all kinds of attitudes and behaviors including sexual abuse, negligence/negligent attitude, commercial or other exploits within the scope of kinship, responsibility, power or trust relationship with the child. In addition that that, the WHO has classified child abuse and neglect into four groups such as physical, emotional, economic, and psychological neglect and abuse (Ramya and Kulkarni 2011; World Health Organization, 2014).

Besides, the etiology of child neglect and abuse has any factors like Mother's low education level, mother's young age, parents' absence, parents with neglect, abuse stories, parents with psychiatric disturbances, low socio-economic level, and substance dependence of parents, unwanted pregnancy and having a stepmother or father are among these factors (Mulita, 2014).

Child physical abuse is an important cause of pediatric morbidity and mortality and is associated with major physical and mental health problems that can extend into adulthood (Babatsikos, 2010). Child abuse has a negative effect on health of children. Considering the numerical dimensions of child neglect and abuse, data have showed 
that 31,000 children under the age of 15 years old per year have lost their lives due to abuse, and millions of children have been exposed to neglect and abuse(Mulita, 2014). A study conducted in Turkey reported that children at the age of $7-18$ in Turkey, 56\% were physically abused, $49 \%$ were emotionally abused, $10 \%$ were sexually abused, $25 \%$ were neglected, $43 \%$ were physically neglected, $3 \%$ were sexually neglected, and 51\% were emotionally neglected (UNICEF, 2010).

An interviewed conducted by Catharine 2019 stated that in Iraq there are many types of child abuse mostly are caused by stepmothers (Kurdistan 24 Interview, 2019). So that, this research addressed the socio economic characteristics of mothers of abused child as well as find out the common types of physical child abuse which were used in Kurdistan societies.

\section{Objectives of the Study}

1. To assess sociodemographic characteristics of mothers

2. To find the most common types of physical abuse among children

3. To find out the association of study sample and most common types of physical abuse among children.

\section{SUBJECTS AND METHODS}

\section{Design of the Study}

This descriptive study was conducted on Mothers of Abused Child at Mala A fandi Health Care Centre in Erbil city of Kurdistan region of Iraq. The study was conducted on a convenient sample (not representative of Erbil city) of 100 mothers who visited Mala A fandi Health Care Centre for Medical seeking. As stated by (Jager et al., 2017), convenient sampling is regarded one of the quickest sampling methods in clinical research. The inclusion criteria were Kurdish Mothers who have children $<15$ years old visited the Health center and who did consent informed.

\section{Data Collection}

The data were collected during the period of May 15, 2019-October 20, 2019. Exposure to abuse was determined using the questionnaire, which assesses physical abuse. Questioner can be define as a tool, which is purely focus on the set of questions that are given to participants in order to obtain their feedback about study (Cleave, 2020).

Regarding tool for measurement, questionnaire was developed after extensive review of relevant literatures (Hussey and Chang, 2017; Jayawant and Parr, 2018), which consisted of two parts. First part; in this part questions were designed to collect data about socio-demographic characteristics of mothers which included items such as age, occupation level of education, family type, and number of children.

Second Part; was concerned with the most common types of physical abuse was consisted of 17 items of multiple choice include all types of physical abuse used by mothers in children. Questions were categorized as yes or not for answering types of physical abuse.

After designing of questions the researcher sent the study questionnaires to 10 experts from various specialties. Afterward, the researcher adjusted the questionnaires according to expert's comments. Whereas, pilot study was conducted for making sure of reliability of the study questionnaire. Pilot study is a preliminary study where helps the researcher to assess the reliability of questions which used to collect data. Moreover, it helps researcher to estimate the amount of time and money needed for the study (Cadete, 2017)

\section{Data Analysis}

Data were entered analyzed using a statistical package for the social sciences (version 23.0). Descriptive statistics were performed to the socio-demographic characteristics of the participating mothers. Chi-square test was used to test the relationship between mother's socio-demographic characteristics and the most common types of abuse in children. $P$-value was considered significant when it was $<0.05$ and highly significant when it was equal to or $<0.01$.

The study was approved by the Scientific and Ethical Committee at Research Medical Centre, Hawler Medical University. Prior to data collection, official permissions were obtained which involved Mala Afandi Health Care Centre, Directorate of General Health Erbil city. In the commencing of the data collection information about aims and method of data collection were transferred to mothers and gave them time to decide to participate or not, afterword they signed the consent to participate in the study.

\section{RESULTS}

Data regarding socio-economic characteristics were collected in the questionnaire during the participating mother accepting to take part in the study. Descriptive statistics, such as frequencies and percentage were calculated for nominal data.

As shown in Table $1(40 \%)$ of the mothers' ages were between 30 and 39 years. While 36\% were aged between 20 and 29 years. However, only $2 \%$ were aged $<20$ years old. Regarding Mother's level of education, the table shows 
that the greatest number of Mothers $(40 \%)$ had a primary certificate, whereas there were only $(11 \%)$ of the mother had a postgraduate certificate. Regarding types of families, there were more than three quarter $(77 \%)$ of mothers that were in nuclear family types, a majority of them were unemployed. And (59\%) had 3-5 children. The same table has shown that $57 \%$ of mothers had male child.

Table 2, revealed that the common types of abuse used by mothers, majority of them were twisted the child's ear (49\%), pinched the child (48\%), slapped the child's faces or head (45\%), pulled the child's hair (36\%), spanked buttocks (with hand) (32\%), beat the child (31\%) whereas, the less common types of abuse used by mothers were, Burned the child $(0 \%)$, choked the child $(0 \%)$, and put hot pepper in the child's mouth $(1 \%)$.

Table 3 shows the association between level of education of mothers and common types of physical abuse reveals that there was statistically significant association between the level education of mothers and Pinched the child used by the mother at $P<0.05$ in which highest percentage $(22 \%)$ was observed in Primary school level while lowest level $(1 \%)$ in postgraduate which was a high level of education mother.

Table 1: Mother's distribution according to their Socioeconomic characteristics

\begin{tabular}{|c|c|c|}
\hline Socio-economic characteristics & $F$ & $\%$ \\
\hline \multicolumn{3}{|l|}{ Age of mother } \\
\hline$<20$ & 2 & $2 \%$ \\
\hline 20-29 & 36 & $36 \%$ \\
\hline $30-39$ & 40 & $40 \%$ \\
\hline $40-49$ & 18 & $18 \%$ \\
\hline $50-59$ & 4 & $4 \%$ \\
\hline \multicolumn{3}{|l|}{ Level of education of mother } \\
\hline Illiterate & 17 & $17 \%$ \\
\hline Primary & 40 & $40 \%$ \\
\hline Secondary & 25 & $25 \%$ \\
\hline Institute/college & 7 & $7 \%$ \\
\hline Postgraduate & 11 & $11 \%$ \\
\hline \multicolumn{3}{|l|}{ Family types } \\
\hline Nuclear family & 77 & $77 \%$ \\
\hline Extended family & 23 & $23 \%$ \\
\hline \multicolumn{3}{|l|}{ Occupation of Mother } \\
\hline Employed & 15 & $15 \%$ \\
\hline Non-employed & 85 & $85 \%$ \\
\hline Total & 100 & $100 \%$ \\
\hline \multicolumn{3}{|l|}{ Number of children in Family } \\
\hline$\leq 2$ & 35 & $35 \%$ \\
\hline $3-5$ & 59 & $59 \%$ \\
\hline$\geq 6$ & 6 & $6 \%$ \\
\hline \multicolumn{3}{|l|}{ Sex of child Sex of child } \\
\hline Male & 228 & $57 \%$ \\
\hline Female & 175 & $43 \%$ \\
\hline Total & 403 & $100 \%$ \\
\hline
\end{tabular}

F: Frequency, \%: Percentage
In Table 3 have showed that there was significant association between the type of family and pulled the child's hair $P<0.05$ in which more common types of physical abuse (pulled the child's hair) was noted in the nuclear type of family (32\%). Table 3 also has showed that there was significant association between occupation of mothers and slapped the child's face or head at $P<0.05$, it was shown that the most common types of physical abuse (Slapped the child's face or head) was in unemployed mother $(42 \%)$.

Table 3 also showed that there were significant statistical differences between numbers of children in family and slapped the child's face or head (34\%) and pinched the child $(35 \%)$ at $p$ value $<0.05$, that's means the child physical abuse can be seen ore among those family who has large number of children.

\section{DISCUSSION}

The results of this study show that the highest percentage of mothers age was within the age group (30-39) years, while the lowest percentage was within the age $<20$ years old. The relationship between the age of mothers and types physical abuse. This shows that there was no significant association were detected between the age of mothers and common types of physical abuse (Slapped the child's face or head, pulled the child's hair, pinched the child, and twisted the child's ear). This result is supported by Depasquale (2016) and its disagreement with the study done by (Elsaied and Alsehly, 2017) who found that parents comprise $80 \%$ of child maltreatment perpetrators and children born to the youngest mothers are at especially high risk of being

Table 2: Frequency and percentage of types of physical abuse among mothers

\begin{tabular}{lcc}
\hline Types of physical abuse & F & $\%$ \\
\hline Hit the child with an object ((not on buttocks) & 14 & 14 \\
Kicked the child & 5 & 5 \\
Beat the child & 31 & 31 \\
Threatened the child with a knife or gun & 8 & 8 \\
Burned the child & 0 & 0 \\
Choked the child & 0 & 0 \\
Spanked buttocks (with hand) & 32 & 32 \\
Hit the child on buttocks (with object) & 8 & 8 \\
Slapped the child's face or head & 45 & 45 \\
Pulled the child's hair & 36 & 36 \\
Shook the child & 13 & 13 \\
Hit the child with knuckles & 2 & 2 \\
Pinched the child & 48 & 48 \\
Twisted the child's ear & 49 & 49 \\
Forced the child to kneel or stand in an uncomfortable & 5 & 5 \\
position & & \\
Put hot pepper in the child's mouth & 1 & 1 \\
Biting & 3 & 3 \\
Total & & \\
\hline
\end{tabular}

F: Frequency, \%: Percentage 
Table 3: Association between socio-economic characteristics and most common types of physical abused child

\begin{tabular}{|c|c|c|c|c|c|c|}
\hline \multirow{2}{*}{$\begin{array}{l}\text { Socio-economic } \\
\text { characteristics }\end{array}$} & \multicolumn{6}{|c|}{ Common types of used physical abused child } \\
\hline & $\begin{array}{l}\text { Beat the } \\
\text { child (\%) }\end{array}$ & $\begin{array}{l}\text { Spanked buttocks } \\
\text { (with hand) (\%) }\end{array}$ & $\begin{array}{l}\text { Slapped the child's } \\
\text { face or head }(\%)\end{array}$ & $\begin{array}{c}\text { Pulled the } \\
\text { child's hair (\%) }\end{array}$ & $\begin{array}{l}\text { Pinched the } \\
\text { child }(\%)\end{array}$ & $\begin{array}{l}\text { Twisted the } \\
\text { child's ear (\%) }\end{array}$ \\
\hline \multicolumn{7}{|l|}{ Age of mother } \\
\hline$<20$ & $0(0)$ & $1(1)$ & $1(1)$ & $1(1)$ & $1(1)$ & $2(2)$ \\
\hline 20-29 & $13(13)$ & $6(6)$ & $13(13)$ & $9(9)$ & $18(18)$ & $16(16)$ \\
\hline 30-39 & $13(13)$ & $16(16)$ & $21(21)$ & $16(16)$ & $16(16)$ & $16(16)$ \\
\hline 40-49 & $5(5)$ & $6(6)$ & $9(9)$ & $8(8)$ & $10(10)$ & $12(12)$ \\
\hline \multirow[t]{2}{*}{$50-59$} & $0(0)$ & $3(3)$ & $1(1)$ & $2(2)$ & $3(3)$ & $3(3)$ \\
\hline & $P=0.5$ & $P=0.06$ & $P=0.57$ & $P=0.51$ & $P=0.6$ & $P=0.136$ \\
\hline \multicolumn{7}{|c|}{$\begin{array}{l}\text { Level of education of } \\
\text { mother }\end{array}$} \\
\hline Illiterate & $6(6)$ & $7(7)$ & $11(11)$ & $3(3)$ & $6(6)$ & $9(9)$ \\
\hline Primary & $11(11)$ & $11(11)$ & $19(19)$ & $17(17)$ & $22(22)$ & $24(24)$ \\
\hline Secondary & $7(7)$ & $9(9)$ & $12(12)$ & $13(13)$ & $17(17)$ & $11(11)$ \\
\hline Institute/college & $3(3)$ & $2(2)$ & $2(2)$ & $1(1)$ & $2(2)$ & $3(3)$ \\
\hline \multirow[t]{2}{*}{ Postgraduate } & $4(4)$ & $3(3)$ & $1(1)$ & $2(2)$ & $1(1)$ & $2(2)$ \\
\hline & $P=0.8$ & $P=0.85$ & $P=0.053$ & $P=0.062$ & $P=0.009$ & $P=0.16$ \\
\hline \multicolumn{7}{|l|}{ Family types } \\
\hline Nuclear family & $23(23)$ & $26(26)$ & $35(35)$ & $32(32)$ & $39(39)$ & $38(38)$ \\
\hline \multirow[t]{2}{*}{ Extended family } & $8(8)$ & $6(6)$ & $10(10)$ & $4(4)$ & $9(9)$ & $11(11)$ \\
\hline & $P=0.65$ & $P=0.8$ & $P=0.86$ & $P=0.034$ & $P=0.332$ & $P=0.89$ \\
\hline \multicolumn{7}{|c|}{ Occupation of mother } \\
\hline Employed & $4(4)$ & $7(7)$ & $3(3)$ & $3(3)$ & $3(3)$ & $6(6)$ \\
\hline \multirow[t]{2}{*}{ Non-employed } & $27(27)$ & $25(25)$ & $42(42)$ & $4(4)$ & $33(33)$ & $42(42)$ \\
\hline & $P=0.6$ & $P=0.18$ & $P=0.035$ & $P=0.8$ & $P=0.16$ & $P=0.501$ \\
\hline \multicolumn{7}{|c|}{$\begin{array}{l}\text { Number of children in } \\
\text { family }\end{array}$} \\
\hline$\leq 2$ & $9(9)$ & $9(9)$ & $8(8)$ & $9(9)$ & $10(10)$ & $13(13)$ \\
\hline $3-5$ & $20(20)$ & $21(21)$ & $34(34)$ & $25(25)$ & $35(35)$ & $33(33)$ \\
\hline \multirow[t]{2}{*}{$\geq 6$} & $2(2)$ & $2(2)$ & $3(3)$ & $2(2)$ & $3(3)$ & $3(3)$ \\
\hline & $P=0.7$ & $P=0.6$ & $P=0.005$ & $P=0.2$ & $P=0.016$ & $P=0.2$ \\
\hline \multicolumn{7}{|l|}{ Sex of child } \\
\hline Male & $80(20)$ & $80(58)$ & $120(60)$ & $20(20)$ & $27(27)$ & $28(28)$ \\
\hline \multirow[t]{2}{*}{ Female } & $40(11)$ & $48(42)$ & $60(40)$ & $16(16)$ & $21(21)$ & $21(21)$ \\
\hline & $P=0.3$ & $P=0.44$ & $P=0.17$ & $P=0.05$ & $P=0.8$ & $P=0.8$ \\
\hline
\end{tabular}

victimized when compared to children of older mothers. Adolescent mothers tend to have limited cognitive maturity, emotional maturity, and knowledge of child development.

In regard to the common type of abuse used by mothers, revealed that the common types of abuse used by mothers, majority of them were twisted the child's ear, pinched the child, slapped the child's faces or head, pulled the child's hair, spanked buttocks (with hand), beat the child whereas, the less common types of abuse used by mothers, Burned the child, choked the child, and put hot pepper in the child's mouth. This result is in agreement with the research finding which was conducted in Egypt showed that the most commonly used methods were slapping on the face or back of the head. Moreover, parents used to hit their children with bare hands, stick, broom, or belt (Elsaied and Alsehly, 2017). This variation may be explained by the different age groups of the sample, as well as environmental variations.
Concerning to the level of education of mothers, the highest percentage of them had primary certificate, and there was a statistically significant association between the levels education of mothers and pinched the child used by the mother, in which highest percentage was observed in primary school level while lowest level in postgraduate mother same result found in a study conducted by (Franke, 2018). Also, no significant association was seen between level education with Slapped the child's face or head, Pulled the child's hair, and Twisted the child's ear, but we observed that with increasing level of education reduced level physical abuse. This result is in contrast with the research article done in India, stated who mentioned that when parents give more attention and are caring towards the children and discuss child's problem parents and especially mother can understand child better. Mother's education and knowledge are advocated as a significant component for the prevention of child maltreatment or abuse (Pappachan et al., 2017; Franke, 2018). Hence mother's knowledge and 
family involvement in child's well-being and development plays a major role in prevention of child abuse.

In regard to the types of family, the result showed that there was no significant association between type of family with Slapped the child's face or head, and Twisted the child's ear, while there was significant association between type of family and pulled the child's in which more common types of physical abuse (pulled the child's hair) was noted in the nuclear type of family. This result is come with the findings of the study conducted by Oliver and his college (2012), which stated that family structure has an important role in increasing child abuse.

Concerning mother's occupation, more than half of the study sample were unemployed and there was no significant association between occupation of mothers with pulled the child's hair, pinched the child, and twisted the child's ear). However, the table showed the statistical differences with slapped the child face or head. However, generally physical abuse observed in unemployed mothers if compared with employed one. These results are in disagreement with the study done by (Das, 2017; Levendosky et al., 2017) which they indicated that occupation are associated with mother's knowledge of child abuse. Therefore, improvement of societal status of mothers and education can move a step forward to prevent child abuse in future.

The same table has illustrated that there is a relation between number of children in family with the slapped the child face and pinched the child. That means family with a large number of child has more likehood to have physical child abuse in compare to family with a lower number of children this result is come up with the study findings of (Mulita, 2014; Springer et al., 2019), who discover that there was relation between family size and physical child abuse.

\section{CONCLUSION}

This study concluded that the level of education of mothers, as well as number of child in family, have a pivotal role for using physical abuse such as slapping the child face, pulled the child's hair, and spanked buttocks. Therefore, family planning and educating mothers may decrease the degree of incidence of child abuse.

\section{DECLARATION}

We declare that the main text of this research is entirely our work. This work has not previously been submitted wholly or in part for any academic award or qualification other than that for which it is now submitted.

\section{REFERENCES}

Babatsikos, G. 2010. Parents knowledge about preventing child abuse. Child Abuse Rev. 19(2): 107-129.

Cadete, L. 2017. What is a Pilot Study; Used in Social Studies. Available from: https://s4be.cochrane.org/blog/2017/07/31/pilotstudies [Last accessed on 2021 Apr 12].

Centers of Disease Control and Prevention. 2010. Understanding Child Maltreatment. Centers of Disease Control and Prevention, Atlanta, Georgia. Available from: https://www.cdc.gov/ violenceprevention/childabuseandneglect/index.htm [Last accessed on 2021 May 02].

Cleave, P. H. 2020. Research Methodology and Research Methods in Pediatric. Available from: https://howandwhat.net/advantagesdisadvantages-questionnaires [Last accessed on 2021 May 01].

Das, D. 2018. Assessment of knowledge regarding child abuse and its prevention among mothers of selected rural community, West Bengal. Int. J. Sci. Res. 7(4): 1485-1489.

Depasquale, S. 2016. Parental Discipline; when is it Abuse and/ or Crime? Available from: https://nccriminallaw.sog.unc.edu/ parental-discipline-when-is-it-abuse-andor-a-crime [Last accessed on 2021 May 02].

Devi, A. M. and R. Yadav. 2016. Knowledge regarding child abuse among parents. Int J. Adv. Nurs. Manag. 4(3): 44.

Elsaied, H. F. and A. A. Alsehly. 2017. Child physical abuse. Egypt J. 38(2): 1207-126.

Franke, H. A. 2018. Toxic stress: Effects, prevention and treatment. Children (Basel). 1(3): 390-402.

Hussey, J. M. and J. J. Chang. 2017. Child maltreatment in the United States: Prevalence, risk factors, and adolescent health consequences. Pediatrics. 118(3): 933-942.

Jager, J. J., D. L. Putnick and M. H. Bornstein. 2017. More than Just Convenient: The Scientific Merits of Homogeneous Convenience Samples.

Jayawant, S. and J. Parr. 2007. Outcome following subdural haemorrhages in infancy. Arch. Dis. Child. 92(4): 343-347.

Levendosky, A. A. G. A. Bogat and C. Martinez-Torteya. 2017. PTSD symptoms in young children exposed to intimate partner violence. Violence Against Wom. 19(2): 187-201.

Mulita, M. 2014. Physical and physiological child abuse in Ethiopia: Implication for intervention. J. Psychol. Psychother. 4(2): 187-201.

Pappachan, C., J. Philip, J. Pinto and N. A. Kurian. 2017. Knowledge of mothers regarding prevention of child abuse. Innov. J. Nurs. Healthc. 3(1): 7-10.

Ramya, S. G. and M. L. Kulkarni. 2011. Bullying among school children: Prevalence and association with common symptoms in childhood. Indian J. Pediatr. 78: 307.

Springer, K., J. Sheridan, D. Kuo and M. Carnes. 2019. Long-term physical and mental health consequences of childhood abuse: Results from a large population-based sample of men and women. Child Abuse Negl. 31: 517-530.

World Health Organization. 2014. Child maltreatment. Fact Sheet, N150. World Health Organization, Geneva. Available from: http:// www.who.int/mediacentre/factsheets/fs150/en [Last accessed on 2020 Mar 25]. 